\title{
Leer a Gibbon. El texto de The History of the Decline and Fall of the Roman Empire
}

\author{
Reading Gibbon. The Text of The History of the Decline and Fall \\ of the Roman Empire
}

JosÉ A. DELGADO DELGADO*

\begin{abstract}
«That Gibbon is behind date in many details, and in some departments of importance, simply signifies that we and our fathers have not lived in an absolutely incompetent world. But in the main things he is still our master, above and beyond "date"»" 1 .
\end{abstract}

\section{RESUMEN}

El propósito principal de este trabajo es el estudio de la tradición textual de Decline and Fall. Se trata aquí el proceso de composición y publicación de la Historia, así como la vida posterior del texto en las ediciones de Milman, Bury y Womersley.

Se evalúa también, como capítulo final,

las traducciones españolas de Mor de

Fuentes y Sánchez de León Menduiña.

PALABRAS CLAVE:

Historia romana; Historiografía; Edward Gibbon; Decadencia y Caída; Bibliografía y Estudios Textuales.

\begin{abstract}
The main purpose of this paper is the study of the textual tradition of Decline and Fall. I discuss the phases of the creative and editorial process of the History and the afterlife of the text in Milman's, Bury's and Womersley's editions. In the final chapter I judge the Spanish translations of Mor de Fuentes and Sánchez de León Menduiña.
\end{abstract}

KEYWORDS:

Roman History; Historiography; Edward Gibbon; Decline and Fall; Bibliography and Textual Studies.

Recibido el 16 de junio de 2012. Aceptado el 4 de septiembre de 2012

- Profesor Titular de Historia Antigua. Área de Historia Antigua. Departamento de Prehistoria, Antropología e Historia Antigua. Facultad de Geografía e Historia. Universidad de La Laguna. 38071 La Laguna ( $\mathrm{S} / \mathrm{C}$ de Tenerife). E-mail: jadelga @ull.es

${ }^{1}$ BURY, J. B. (ed.), The History of the Decline and Fall of the Roman Empire, vol I. London, 1896, pág. Ixvii. 


\section{DOS MAESTROS Y UNA DISCIPLINA}

Los grandes maestros de una disciplina, como los grandes creadores de arte, resisten incólumes el paso del tiempo. Tienen siempre una enseñanza lista para quien quiera atenderla, son fuente constante de inspiración para quienes los frecuentan con atención y sus obras constituyen bases sólidas sobre las que apoyar nuevos trabajos. Leer, por tanto, a los maestros de cada ciencia o rama del saber es una necesidad inexcusable para quienes la cultivan o se forman en ella.

Por consenso universal de la crítica especializada y lectores cultos, The History of the Decline and Fall of the Roman Empire (en adelante DF) concedió a Edward Gibbon (1737-1794) de una vez y para siempre un puesto de honor entre los más grandes historiadores y hombres de letras de Europa. Por acuerdo unánime de los profesionales de la Historia Antigua, el legado científico de Géza Alföldy (1935-2011) sitúa a nuestro querido profesor entre los mayores historiadores de nuestro tiempo de la Roma de los emperadores. Aunque maestros de mundos, estilos y obras muy distintos, en cierto sentido sus personalidades se complementan para dar cuenta del ayer y el hoy de nuestra disciplina en su más elevada expresión.

En el prefacio del primer volumen de DF Gibbon advertía a sus lectores que la ejecución del vasto plan de la obra requeriría muchos años de salud, meditación y perseverancia, y que la honestidad de su trabajo — seguía en el parágrafo que encabezaba la sección de notas - estaba avalada por la diligencia y rigor con los que había examinado los materiales originales de los que se nutría su relato histórico. Con igual franqueza reconocía también ante su público que la laboriosa empresa que se había impuesto se compensaba suficientemente con el deleite intelectual que le suponía cada una de las horas dedicadas al estudio.

He aquí una exposición clara y sincera de los principios y actitudes básicos que han de guiar el trabajo histórico y que se reconocen de inmediato en la obra de los más grandes historiadores. Géza Alföldy, nuestro generoso maestro, se impuso también la titánica tarea de historiar el Imperio Romano (aunque de una manera bien distinta), y al igual que su ilustre predecesor aplicó a ello todo su inmenso talento, paciente diligencia y extremo rigor. Como para Gibbon, las horas de trabajo eran para él horas sin fin, pero horas felices por la pasión con la que abordaba cada uno de los muchos temas históricos de los que se ocupó en su larga y fecunda carrera.

Si en el sentido expuesto en las líneas precedentes ha de concedérsele a Gibbon el imperecedero mérito de ser el fundador de la tradición histórica moderna sobre el Imperio Romano, a Alföldy ha de reconocérsele el de haber enriquecido, refinado y ampliado esa tradición como muy pocos lo han hecho antes que él (o lo podrán hacer en el futuro, me atrevería a vaticinar). La contribución de Géza Alföldy a la historia y la epigrafía de la época imperial, la Antigüedad Tardía o la historiografía de la antigüedad romana constituye una de las aportaciones más significativas a los estudios históricos de nuestra época y da la verdadera medida del avance de nuestros conocimientos sobre el antiguo Imperio desde los tiempos de Gibbon. 
El legado intelectual de ambos maestros, al margen de sus particularidades y méritos respectivos, forma parte de la historia de nuestra disciplina y reclama la atención de los estudiosos y amantes de la cultura clásica. Pero frente a la lectura «directa» e «inmediata» que se puede hacer de una obra contemporánea como la de Alföldy², la de un viejo clásico como DF requiere en mi opinión contemplar ciertas consideraciones previas relativas a su historia textual. Y este es precisamente el propósito de las páginas que siguen. Quiero pensar que Géza Alföldy, que tanto estimaba a Edward Gibbon, no lo consideraría impropio como motivo de homenaje póstumo.

\section{UNA HISTORIA PARA EL MUNDO}

La publicación de primer volumen de $D F$, en febrero del año 1776, fue todo un acontecimiento en los medios cultos de Londres. Historiadores de la valía de David Hume o William Robertson, políticos de la talla de Horace Walpole y críticos tan severos como Samuel Johnson se rindieron de inmediato, y con ellos toda la sociedad londinense acomodada, a la grandiosa narración histórica (vid. 3.2.2). De la noche a la mañana Edward Gibbon se ganó una reputación sin precedentes como historiador y hombre de letras y todos lo reconocieron como uno de los más grandes ingenios «de la tribu literaria de Europa» ${ }^{3}$. Con la aparición de los sucesivos volúmenes (los tres últimos con fecha de 1788) su fama fue acrecentándose y en el momento de su muerte su genio había conquistado no ya Gran Bretaña, sino todo el continente europeo (vid. cap. 3) y hasta la América recientemente independizada 4 .

Edward Gibbon es, pues, uno de esos poquísimos autores a los que literatos e historiadores reclaman por igual como maestro y a los que el público lector no deja de $\operatorname{admirar}^{5}$ (Figura 1).

Su posición entre los hombre de letras se funda en gran medida en su particular y distintivo estilo, «puro, elegante y preciso», según la opinión de algunos de sus contemporáneos ${ }^{6}$. Su antigua familiaridad con los grandes oradores latinos de-

\footnotetext{
2 La relación completa de todas sus contribuciones científicas se encontrará en la página web del Seminar für Alte Geschichte und Epigraphik de la Universidad de Heidelberg (www.uniheidelberg.de/fakultaeten/philosophie/zaw/sag/alfoeldy.html).

${ }^{3}$ SHEFFIELD, Lord (ed.), The Miscellaneous Works of Edward Gibbon, Esq., vol. II. London, 1814, pág. 429 (carta de Adam Smith).

${ }^{4}$ Se conserva una edición de DF con la firma autógrafa de Washington en la página del título de cada volumen (excepto en el primero): THOMPSON, J. W., «The Library of Gibbon the Historian», The Library Quarterly, 7, (1937), pp. 351-352.

${ }^{5}$ De las biografías sobre el autor, son especialmente valiosas las de LOW, D. M., Edward Gibbon, 1737-1794. London - New York, 1937; CRADDOCK, P. B., Young Edward Gibbon: Gentleman of Letters, Baltimore, 1982; Eadem, Edward Gibbon, Luminous Historian 1772-1794. Baltimore, 1989; de entre las biografías breves, mantiene todavía su importancia la de BURY, J., «Edward Gibbon», Encyclopædia Britannica, 11, $1911^{11}$, pp. 927-936 y desde luego la más reciente de CHRIST, K., Von Gibbon zu Rostovtzeff. Leben und Werk führender Althistoriker der Neuzeit. Darmstadt, 1972, pp. 8-25 y 356-357.

${ }^{6}$ SHEFFIELD, Lord, op. cit., pág. 152 (carta de Joseph Warton).
} 


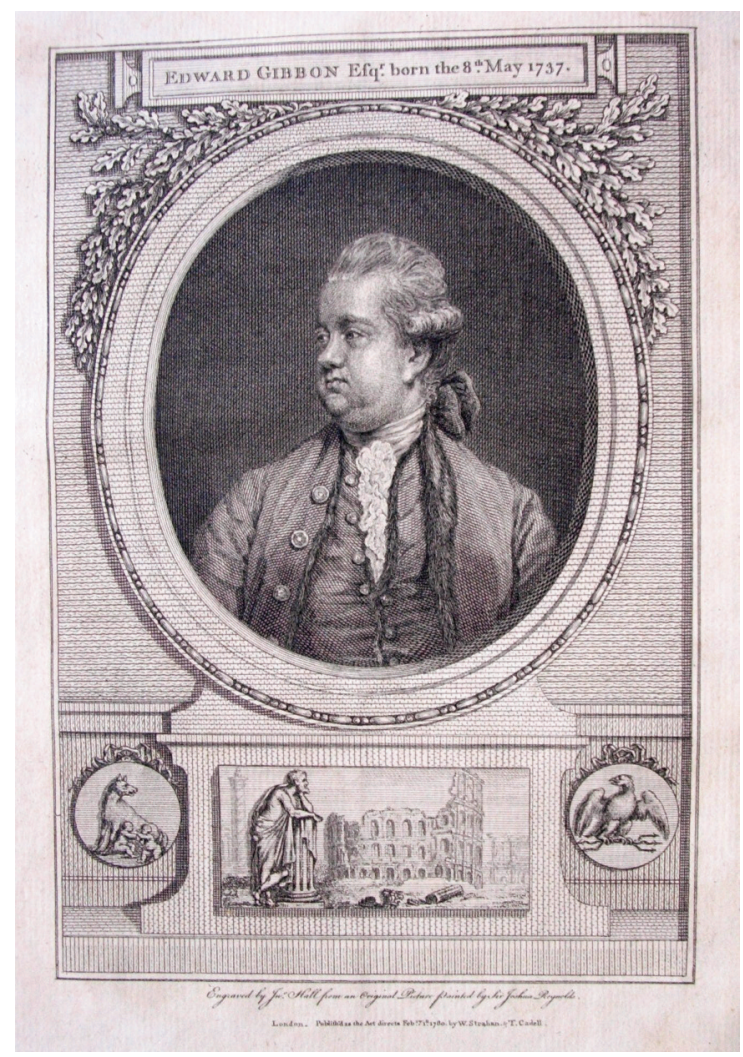

Fig. 1. Retrato de Edward Gibbon. Grabado por John Hall como frontispicio para DF I (1776).

bió sin duda ayudarle a modelarlo ${ }^{7}$. La forma literaria de su prosa fue una de sus principales preocupaciones en todas las fases de composición de $D F^{8}$.

Es este principio de orden estético una de las razones fundamentales por las que $D F$ ha resistido al paso del tiempo. La otra es naturalmente el interés del tema elegido y la originalidad y maestría con que Gibbon lo aborda.

Su extraordinario relato histórico de las causas del declive y caída de la civilización antigua y su paulatina sustitución por un nuevo orden de cosas, que contempla la historia del mundo mediterráneo desde el reinado de Marco Aurelio hasta la toma de Constantinopla por los turcos a mediados del siglo XV, no ha dejado de cautivar (aunque no necesariamente por las mismas razones) a siete generaciones de literatos, lectores cultos e historiadores.

${ }^{7}$ Cf. LOW, D. M., op. cit., pág. 328.

${ }^{8}$ Sobre su «arte literario», véanse BOND, H. L., The Literary Art of Edward Gibbon. Oxford, 1960; BRAUDY, L., Narrative Form in History and Fiction: Hume, Fielding and Gibbon. Princeton, 1970. 
«Recorrer el Decline and Fall», escribe Borges" ${ }^{9}$, "es internarse y venturosamente perderse en una populosa novela, cuyos protagonistas son las generaciones humanas, cuyo teatro es el mundo, y cuyo enorme tiempo se mide por dinastías, por conquistas, por descubrimientos y por la mutación de lenguas y de ídolos». Como el escritor argentino, muchísimos lectores anónimos se han sentido igualmente subyugados por DF a lo largo ya de doscientos treinta años, consiguiendo así que la obra nunca haya dejado de reeditarse desde 1776 y que haya sido traducida (total o parcialmente) a la mayor parte de las lenguas europeas (cf. cap. 3).

Los historiadores, por su parte, han admirado y apreciado particularmente en Gibbon su talento, su honestidad en el tratamiento de las fuentes, su enorme erudición, su mirada crítica y mordaz, sus juicios ponderados y, claro está, la propia «arquitectura» de su obra ${ }^{10}$. En ese sentido no parece impropio alinearlo en la mejor tradición historiográfica clásica representada por Tucídides o Tácito. En cualquier caso, entre sus contemporáneos era considerado el más apto y cualificado historiador que había producido el siglo XVIII ${ }^{11}$ y todavía la erudición alemana del XIX estimaba DF como una obra histórica de referencia. Barthold Georg Niebuhr comentaba en 1828 a sus alumnos de la Universidad de Bonn que no se podría avanzar en la historia del Imperio más allá de lo que lo había hecho Gibbon $^{12}$, y aún en 1885 Theodor Mommsen explicaba a los suyos de Berlín que seguía siendo la mejor historia general del Imperio Romano disponible ${ }^{13}$. En la actualidad, los historiadores del mundo antiguo seguimos estudiando su influencia en la formación de la moderna historiografía sobre el Imperio Romano ${ }^{14}$ y el modo en que aún condiciona nuestra visión de la Antigüedad Tardía ${ }^{15}$ o la civilización bizantina $^{16}$.

${ }^{9}$ BORGES, J. L., Obras Completas, vol. II. Barcelona, 2005, pág. 559 (la cita original es de 1961).

${ }^{10}$ Entre los estudios generales sobre DF como obra histórica, cabe destacar: DUCREY, P., et alii (eds.), Gibbon et Rome à la lumière de l' historiographie moderne. Geneva, 1977; BOWERSOCK, G. W., et alii (eds.), Edward Gibbon and the Decline and Fall of the Roman Empire. Cambridge (Mass.), 1977; WOMERSLEY, D., The Transformation of The Decline and Fall of the Roman Empire. Cambridge, 1988; MCKITTERICK, R. y QUINAULT, R. (eds.), Edward Gibbon and Empire. Cambridge, 1997.

11 Vid. 3.2.2.; además, BENTLEY, M. (ed.), Companion to Historiography. London-New York, 1997 (reimp. 2002), pp. 271-276.

${ }^{12}$ SCHMITZ, L. (ed.), Lectures on the History of Rome by B. G. Niebuhr, vol. III. London, 1849², pp. 299-300. Sobre la superioridad textual de la versión inglesa de las Lectures sobre la alemana (al cuidado de ISLER, M., Vorträge über römische Geschichte, an der Universität zu Bonn gehalten. I-III. Berlin, 1846-1848), léase la introducción de Schmitz en el volumen I, pp. iii-viii.

${ }^{13}$ WIEDEMANN, T. (ed.), Theodor Mommsen. A History of Rome under the Emperors (based on the lecture notes of Sebastian and Paul Hensel 1882-1886). London - New York, 1996, pág. 372.

${ }^{14}$ MOMIGLIANO, A., «La formazione della moderna storiografia sull' Impero romano», Contributo alla Storia degli Studi Classici, Roma, 1955, pp. 107-164 (particularmente 137-143); Ídem, “Gibbon” s contribution to historical method», ibídem, pp. 195-211.

${ }^{15}$ CAMERON, A., et alii (eds.), Late Antiquity: Empire and Successors, A. D. 425-600 (CAH XIV). Cambridge, 2000; WARD-PERKINS, B., La caída de Roma y el fin de la civilización. Madrid, 2007 (ed. orig. 2005), pp. 13-27; DEMANDT, A., Die Spätantike. München, 2007², especialmente pp. xv-xxi, 579609; ROUSSEAU, PH. (ed.), A Companion to Late Antiquity. Oxford, 2009, particularmente pp. 59-92.

${ }^{16}$ JEFFREYS, E., et alii, «Byzantine Studies as an academic discipline», en JEFFREYS, E. (eda.), The Oxford Handbook of Byzantine Studies. Oxford, 2008, pp. 3-20. 
En síntesis, la grandeza y atemporalidad de la monumental historia de Gibbon reside, en parte, en la rara combinación de una extraordinaria erudición y sagacidad históricas con una prosa elegante, directa y precisa, salpicada de humor, ironía e irreverencia en no pocas ocasiones. La otra parte no menos importante de sus méritos descansa en su original trabajo bajo el modelo contemporáneo de la «historia filosófica», que eleva y perfecciona al apoyar con fuentes y bibliografía sus consideraciones acerca del sentido de la Historia, la civilización y la naturaleza de los hombres ${ }^{17}$.

\section{EL TEXTO DE DECLINE AND FALL}

\subsection{Introducción a la tradición textual}

La evaluación de los méritos de una obra literaria o histórica está siempre condicionada, aun siquiera sutilmente, por la forma en que se da a conocer al público. La reputación de un autor descansa pues, al menos en cierta medida, en la edición a través de la que lo conocen sus lectores. En estas circunstancias se comprenderá la importancia que reviste el conocimiento de la historia editorial de una obra. En el caso de un texto «clásico» como $D F$, que vio múltiples ediciones en vida del autor y que se ha perpetuado en el mercado editorial ininterrumpidamente desde su muerte hasta nuestros días, el estudio de su tradición textual es aún más necesario.

Los contemporáneos de Gibbon lo pudieron leer en dos formatos diferentes (cuarto y octavo) y hasta en ocho «estados» distintos. Los lectores de la era victoriana leyeron el Gibbon del reverendo Henry Milman, los del siglo XX, el del historiador John Bury, y los del presente siglo XXI leemos el del profesor de literatura inglesa David Womersley. Cada una de estas «versiones» de DF, con sus particulares criterios de edición, introducciones, aparatos de notas, apéndices e índices, determina indefectiblemente la apreciación de Gibbon, pues cada una de ellas sugiere una lectura distinta del historiador a la que difícilmente puede sustraerse del todo su público.

Para los lectores de lengua no inglesa, la traducción se convierte en un filtro más que mediatiza sus impresiones de la obra y el autor. Las versiones de DF al español son ejemplos paradigmáticos de hasta qué punto una traducción puede condicionar la estimación de una obra. La traducción de José Mor de Fuentes de 1842, todavía la única castellana íntegra en sentido estricto, es tan poco fiel a la letra y espíritu del texto inglés que es realmente difícil creer que se está leyendo a

${ }^{17}$ Sobre el ambiente intelectual en que se forjó la obra de Gibbon son fundamentales los estudios de POCOCK, J. G. A., Barbarism and Religion, I: The Enlightenments of Edward Gibbon. Cambridge, 1999; Ídem, Barbarism and Religion, II: Narratives of Civil Government. Cambridge, 1999; Ídem, Barbarism and Religion, III: The First Decline and Fall. Cambridge, 2003; Ídem, Barbarism and Religion, IV: Barbarians, Savages and Empires. Cambridge, 2005; Ídem, Barbarism and Religion, V: Religion, The First Triumph. Cambridge, 2011. 
Gibbon. La recentísima de José Sánchez de León Menduiña, en curso de publicación este año 2012, es en realidad una versión parcial (que desecha a la ligera todas las notas originales), muy poco cuidada textualmente y con una obsoleta y desafortunada presentación del autor y su obra.

\subsection{La composición y publicación de Decline and Fall}

\subsubsection{La composición de Decline and Fall I}

Sólo en raras ocasiones se pueden seguir los pasos de los grandes maestros en el proceso creativo de la composición de sus obras, pues es poco frecuente que se conserven los manuscritos autógrafos o existan referencias autobiográficas. El caso de Gibbon es una feliz excepción, pues si bien se desconoce el paradero de los manuscritos de $D F$ al menos se han preservado sus Memorias $^{18}$ y una parte considerable de su correspondencia ${ }^{19}$. La publicación póstuma de ambos legados ha permitido conocer importantes detalles de la composición de DF que nunca hubieran podido deducirse del texto impreso.

Edward Gibbon hacía remontar a su juventud su interés por la historia, cuando ya leía con avidez y resumía con disciplina los «clásicos» de la Antigüedad, particularmente los latinos (M, 56-58, 120-121, 222-224). Recuerda que su atención se dirigió principalmente hacia los periodos más tardíos de la época imperial romana, la historia bizantina y la oriental, que lo fascinaron desde sus primeras lecturas ${ }^{20}$. Revelan también sus Memorias una temprana y refinada sensibilidad literaria, un cierto gusto por la reflexión filosófica —que habría de fortalecerse en su madurezy vocación para la creación intelectual ${ }^{21}$.

El Grand Tour (1763/65) sería el acontecimiento capital que le descubriría la manera de aunar su pasión por la historia, su talento literario y sus inquietudes creativas. «[Fue] el 15 de octubre [de 1764]», escribe en sus Memorias (M, 270, 302, 405-406) 22, «una melancólica tarde, estando sentado y pensativo en el Capitolio, mientras los frailes descalzos cantaban sus letanías en el templo de Júpiter,

18 Sigo la edición definitiva MURRAY, J. (ed.), The Autobiographies of Edward Gibbon. London, 1896, que contiene las seis versiones que de sus Memorias redactó Gibbon. Mis citas se incorporan en el cuerpo del texto entre paréntesis (M), con indicación de página.

${ }^{19}$ Sigo la edición de PROTHERO, R. E. (ed.), The Private Letters of Edward Gibbon, 2 vols. London, 1896. Mis citas se incorporan en el cuerpo del texto entre paréntesis (L), con indicación de volumen (en números romanos) y página (en arábigos).

${ }^{20}$ Prueba de esa pasión juvenil por la «historia exótica» es la composición de un ensayo titulado The Age of Sesostris (1752). Quemó el manuscrito veinte años después, en 1772, al encontrarlo casi por casualidad en el fondo de una gaveta (M, 79-81, 122, 225) .

${ }^{21}$ De lo que da fe su primer trabajo impreso, titulado Essai sur l' étude de la littérature, publicado en «duodécimo» en Londres por Becket y Hondt en 1761 (cf. M, 167-172).

${ }^{22}$ Este rapto de inspiración lo relata Gibbon en tres versiones ligeramente distintas. Traduzco aquí la del manuscrito D, que se corresponde con las páginas 405/6 de la edición de referencia. 
cuando me sobrevino por primera vez la idea de mi historia. Pero mi plan original se circunscribía al declive de la Ciudad...».

Habrían aún de pasar algunos años entre ese momento de inspiración y las primeras incursiones serias en «tan laborioso trabajo» (M, 406). No fue hasta 1768 «cuando gradualmente comencé a avanzar desde el deseo a la esperanza, de la esperanza al diseño, del diseño a la ejecución, de mi trabajo histórico, de cuyos límites y extensión tenía por entonces una noción muy poco adecuada» (M, 411412). Pacientemente empezó a reunir y organizar las fuentes originales y la literatura erudita para su historia: los historiadores griegos y latinos desde Tácito hasta Amiano Marcelino, la Historia Augusta, «los rayos subsidiarios de medallas e inscripciones», los volúmenes de Tillemont, los Anales y la Antigüedades de Italia de Muratori, el Código Teodosiano con el comentario de Godefroy... (M, 284-285, 303).

Obligaciones de distinta naturaleza y especialmente la enfermedad y muerte de su padre lo distrajeron de sus investigaciones más de lo que él hubiera deseado entre los años 1770 y 1772 (M, 285, 288-289). Pero una vez instalado en su casa de Londres en octubre de 1772, gozando ya de una relativa independencia económica y disponiendo de una biblioteca por ese tiempo muy notable, comenzó a trabajar en la composición del primer volumen de su historia (M, 306307). «Al principio todo era oscuro y dudoso», confiesa Gibbon (M, 308), «incluso el título del trabajo, la auténtica era de la Decadencia y Caída del Imperio, los límites de la introducción, la división de los capítulos y el orden de la narración; a menudo estuve tentado de abandonar el trabajo de siete años». Por fortuna no lo hizo. Pero ahora quedaba la delicada cuestión del estilo que habría de imprimir a su narración histórica, que no sólo era un asunto de sensibilidad personal, sino que sabía bien que afectaría decisivamente a la recepción pública de su obra. «Tres veces», escribe (M, 308), «compuse el primer capítulo, y dos el segundo y tercero, hasta quedar tolerablemente satisfecho con su resultado». Nunca dejó de preocuparle la forma estética de su composición y, como se verá más adelante, siguió depurando estilísticamente su texto en todas y cada una de las sucesivas ediciones de DF.

Así pues, mientras tomaba decisiones sobre los contenidos y extensión de cada capítulo corregía una y otra vez el estilo de su prosa, en ocasiones con el consejo de sus más íntimos amigos (a quienes leía algún pasaje de tarde en tarde [M, 308-309]). De esta manera fue adquiriendo cuerpo, paso a paso, el primer volumen de su Historia. Y así, en junio de 1775 el manuscrito estaba ya listo para la imprenta (M, 310-311).

\subsubsection{La publicación de Decline and Fall I}

Los primeros contactos de Gibbon con el editor Thomas Cadell se remontan al verano de 1774, como documenta una carta $(L, I, 221)$ en la que el historiador comenta a su buen amigo John Baker Holroyd (Lord Sheffield) el interés mostrado por 


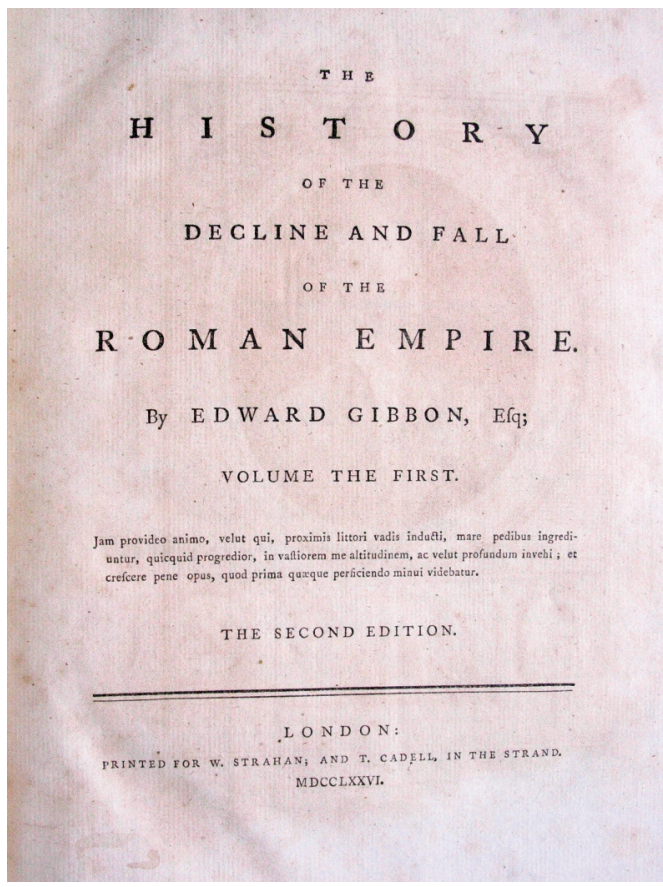

Fig. 2. Página de portada de la segunda edición en 'cuarto' de DF I (1776).

Cadell para publicar su obra. No sería, sin embargo, hasta el junio del año siguiente cuando se formalizaría el acuerdo, sellado también con el impresor William Strahan $(\mathrm{M}, 311)$. Esta relación se iba a prolongar aún veinte años más, pues «Strahan and Cadell» fueron los únicos titulares de los derechos de DF en vida de su autor.

Thomas Cadell era por aquel entonces el único propietario de la más importante casa editorial de Londres, reconocida por sus generosos pagos a escritores de renombre ${ }^{23}$. Habitualmente se asociaba con el eminente impresor William Strahan, figura central del comercio librero británico de su época ${ }^{24}$. Entre ambos dieron a la luz algunos de los más celebrados libros de historia de la segunda mitad del siglo XVIII: The History of England (1754-1762), de David Hume, The History of the Reign of the Emperor Charles V(1769), de William Robertson, o An Inquire into the Nature and Causes of the Wealth of Nations (1776), de Adam Smith.

Los trabajos de composición tipográfica, impresión y corrección de pruebas (que se asignó el propio Gibbon) comenzaron en el mismo mes de junio de 1775

${ }^{23}$ LAW, G., «Cadell family», en SUAREZ, M. F. y WOUDHUYSEN, H. R. (eds.), The Oxford Companion to the Book, I. Oxford, 2010, pág. 577.

${ }^{24}$ FINDLAY, B. , «Strahan, William», en SUAREZ, M. F. y WOUDHUYSEN, H. R. (eds.), op. cit., II, pp. 1181-1183. 


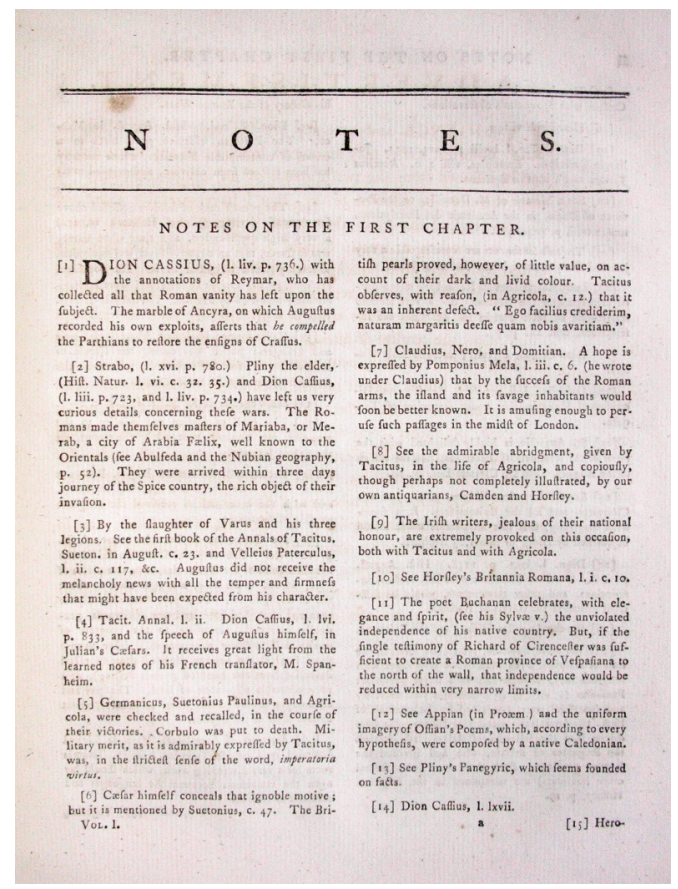

Fig. 3: Primera página de la sección de notas de la segunda edición en 'cuarto' de DF I (1776).

(L, I, 261; cf. L, I, 273), con una tirada prevista inicialmente de 500 ejemplares, finalmente doblados gracias «al olfato profético del Sr. Strahan» (M, 311). Siete meses más tarde, el diecisiete de febrero de 1776, Thomas Cadell ponía a la venta el primer volumen de $D F(\mathrm{M}, 311 ; \mathrm{L}, \mathrm{I}, 279)$ al respetable precio de una guinea para los ejemplares sin encuadernar ${ }^{25}$.

El libro que acababa de aparecer como gran novedad editorial era un elegante y notable cuarto $\left(27.5 \times 22 \mathrm{cms}\right.$.) de setecientas páginas ${ }^{26}$, cuidada tipografía (que emplea el tipo Caslon, característicamente inglés ${ }^{27}$ ) y generosos márgenes (Figura 2), que se abre con un retrato de Gibbon a modo de frontispicio (grabado por John Hall a partir de un óleo de Sir Joshua Reynolds [vid. Figura 1]). Sus lectores lo conocieron en dos estados ligeramente diferentes desde el punto de vista textual, pues la decisión de doblar el número de ejemplares cuando la impresión estaba ya bien avanzada implicó la recomposición de toda la primera parte del tex-

${ }^{25}$ Así consta en el listado de libros a la venta de la firma que se imprimió al final del tercer volumen de $D F$.

${ }^{26}[\mathrm{xii}]+\mathrm{viii}+[\mathrm{iv}]+586+[\mathrm{ii}]+$ Ixxxviii $+[\mathrm{ii}]$. 590-591.

27 LANE, J. A., «Caslon family», en SUAREZ, M. F. y WOUDHUYSEN, H. R. (eds.), op. cit., I, pp. 


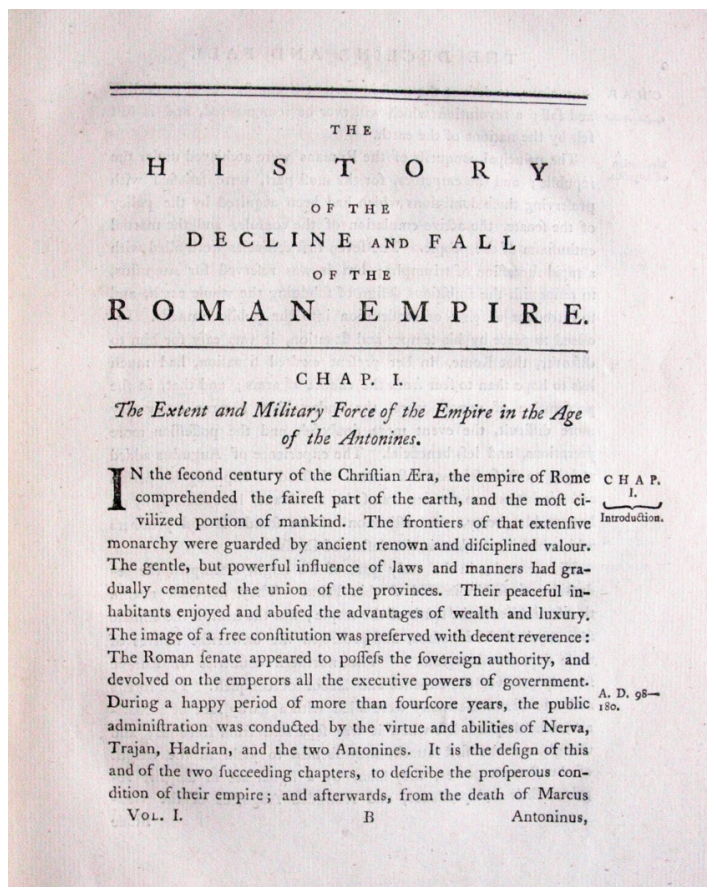

Fig. 4: Primera página del primer capítulo de la segunda edición en 'cuarto' de DF (1776).

to (teniendo en cuenta que en esa época se imprimía «por formas» ${ }^{28}$ ), con la consiguiente incorporación de correcciones.

La narración se organizaba conceptualmente en dieciséis capítulos, cada uno de los cuales se acompañaba de un sólido y nutrido aparato erudito en forma de notas impresas al final del volumen (con un total de 1662 [Figura 3]). Se podía seguir a través de ella la primera parte de la «memorable serie de revoluciones que en el curso de trece siglos minarían gradualmente, y a la larga destruirían, la sólida estructura de la grandeza romana» ${ }^{29}$. La «extraordinaria revolución» comenzaba con el reinado de Trajano y los Antonino, «periodo en que la monarquía romana había alcanzado su madurez» (Figura 4), y se extendía hasta la época de Constantino, «cuando ya caminaba hacia su declive».

${ }^{28}$ En la época de la imprenta manual, el impresor imprimía el libro por pliegos, requiriéndose dos formas (una para el blanco, otra para la retiración), conteniendo cada una el número de moldes exigido por el formato correspondiente y en la disposición adecuada para que impresas las dos caras y doblado el número de veces necesario el texto de las páginas impresas ofrezca una lectura continua. Este sistema «por formas» venía impuesto principalmente por las limitaciones materiales de la imprenta, que no disponía de los tipos suficientes para componer seguidas todas las planas que entran en las formas de un pliego. Sobre estas cuestiones tipográficas se leerá con provecho RICO, F., El texto del «Quijote». Preliminares a una ecdótica del Siglo de Oro. Barcelona, 2005, pp. 81-86, 172-208.

${ }_{29} D F$, I, Preface. 


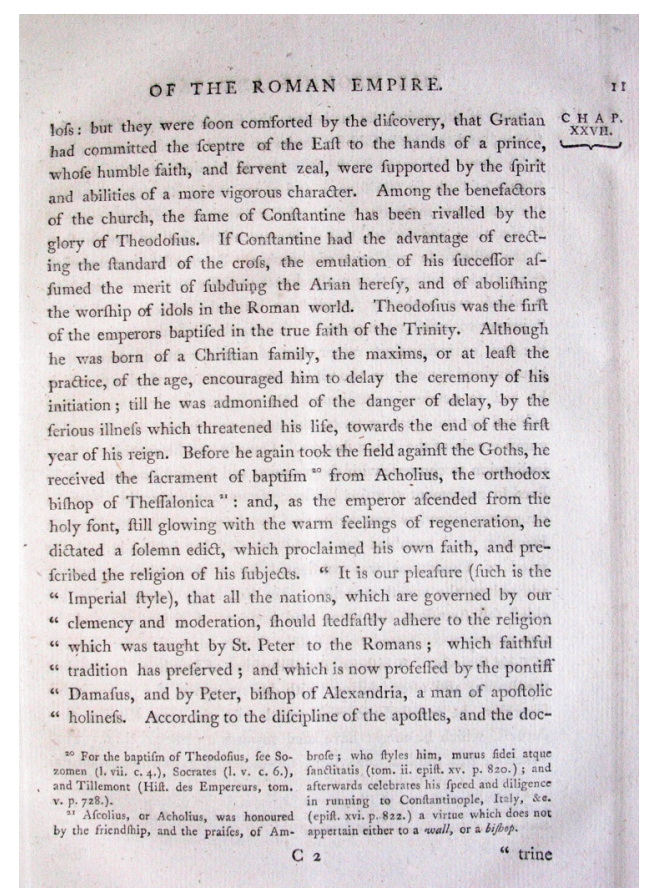

Fig. 5: Página 11 de la primera edición en 'cuarto' de DF III (1781), correspondiente al capítulo XXVII.

El éxito de la obra fue inmediato. «Mi libro estaba en cada mesa y casi en cada "toilette"», recordaba Gibbon (M, 311). La tirada completa se agotó «en unos pocos días» y, mientras en Londres se vislumbraba la necesidad de imprimir una segunda y hasta una tercera edición, los «piratas de Dublín» se aprestaban a invadir los derechos de propiedad de los editores legítimos (L, I, 288). William Robertson y David Hume, buenos amigos y críticos autorizados, se apresuraron a felicitarlo y Gibbon guardó siempre un recuerdo emocionado y agradecido particularmente por la carta que le escribió el segundo (M, 311-313), ya casi en sus últimos días. Pero no sólo era Inglaterra la que se rendía ante el genio de Gibbon. En diciembre de ese mismo año recibió el historiador inglés en su casa de Bentinck Street los siete primeros capítulos de su $D F$ en una traducción francesa en curso de publicación a cargo de Le Clerc de Septchênes, «fiel y elegante... si bien con un pequeño número de pasajes con los que estoy menos contento de la traducción» (L, I, 296-298; cf. L, I, 292-293) ${ }^{30}$.

${ }^{30}$ Se publicó como Histoire de la décadence et de la chute de l'Empire romain. Traduite de l' anglais de M. Gibbon par M. de Septchênes. Paris, 1777-1795. 18 vols. in-8o. Gibbon tenía en su biblioteca los tres primeros volúmenes (KEYNES, G., The Library of Edward Gibbon. A Catalogue of his Books. London, 1940, pág. 134). Le Clerc de Septchênes, secretario de Luis XVI, tradujo en realidad sólo los tres primeros volúmenes (con fecha de 1777); los restantes estuvieron al cargo de manos menos expertas. Gibbon había pensado originalmente en Antoine Suard, reconocido traductor francés de obras inglesas de historia, para traducir su DF, pero los contactos no dieron resultado (L, I, 292-293). 
Pero desde luego el texto no se recibió tampoco sin polémica. Los dos últimos capítulos de DF, en los que Gibbon argüía una relación causal entre el ascenso del cristianismo y el declive del Imperio, fueron bien pronto objeto de amplio y agrio debate (M, 316-319; L, I, 295) ${ }^{31}$. Como respuesta el historiador daría a la imprenta en 1779 su A Vindication of Some Passages in the Fifteenth and Sixteenth Chapters of the History of the Decline and Fall of the Roman Empire, célebre desde entonces por la contundencia de sus argumentos y la sutileza e ironía de su prosa.

Tal y como se había previsto, la demanda del público exigió una segunda edición del volumen, publicada en junio de ese mismo año con una tirada ahora de 1500 ejemplares (L, I, 285), a la que siguió una tercera en 1777, una cuarta en 1781, una quinta (en dos estados distintos) en 1782 y una sexta y última en 1789. Ninguna de ellas reproduce exactamente el mismo texto. Gibbon revisaba cada nueva edición, introduciendo modificaciones relativas a estilo y ocasionalmente contenido, lo que produjo como resultado un elevado número de variantes.

Al margen de las distintas lecturas generadas por este proceso de revisión continua, la decisión editorial que más consecuencias habría de tener para la estimación de $D F$ sería la del traslado de las notas finales al pie de página (Figura 5). Esta idea partió originalmente de una sugerencia de Hume a Strahan, pero el impulso definitivo para su adopción llegó, paradójicamente, con la aparición de la edición «pirata» de Dublín. En una carta fechada el 25 de septiembre de 1776 Gibbon elogia la calidad de su impresión y queda sorprendido al comprobar que «las notas al pie ocupan mucho menos espacio del que podría haber imaginado» (L, I, 288). La decisión estaba tomada. El 29 de marzo de 1777 escribió, orgulloso, a su madrastra (L, I, 304): «el declive del Imperio Romano no decae aún, la polémica remite, las ventas continúan y estamos ahora imprimiendo una tercera edición en cuarto de 1000 ejemplares (con un total [acumulado] de 3500) con las notas al pie». Con las notas bajo el texto, los lectores podrían al fin apreciar sin dificultad la solidaria y estimulante relación que Gibbon había establecido entre la narración histórica propiamente dicha y las fuentes y bibliografía que la apoyaban.

\subsubsection{Decline and Fall II-III}

Casi dos años transcurrieron entre la publicación del primer volumen y el comienzo de la composición del segundo (M, 315). Durante ese tiempo los intereses intelectuales de Gibbon se habían fijado en cuestiones bien ajenas a su Historia (siguió cursos de Anatomía, Química e Historia Natural y se perdió en la maraña de la «controversia aria» [M, 315]) y no fue capaz de ordenar «con claridad ni perspicacia» las vicisitudes del reinado de Constantino (aunque ya estaba «profundamente inmerso» en el trabajo en 1776 [L, I, 285]). «Tal era mi disconformidad con el primer ensayo», se lamenta Gibbon ( $\mathrm{M}, 315-316)$, «que arrojé a las llamas

${ }^{31}$ A pesar de que su redacción fue muy meditada, pues fue revisada tres veces antes de considerarla definitiva $(\mathrm{M}, 308)$. 
unos cincuenta folios». Pasado ese periodo de disipación, se sintió con nuevos ánimos y a comienzos de 1778 volvió a retomar su Historia con determinación y seguridad. Componía y luego memorizaba largos parágrafos, «suspendiendo la acción de la pluma hasta no haber pulido del todo el trabajo». De esta manera escribía cada día a mejor ritmo y corregía y desechaba cada vez menos. Ahora se sentía de nuevo dueño de su estilo y maestro de su materia (M, 316).

La composición debió marchar a buen ritmo durante los años 1778 y 1779, a pesar del silencio de Gibbon ${ }^{32}$, pues en una carta a su madrastra fechada el 27 de junio de 1780 le anuncia que está ya revisando y corrigiendo pruebas de imprenta de los dos próximos volúmenes de su Historia, cuya publicación estaba prevista para el invierno siguiente (L, I, 382). En noviembre de 1780 ya se había terminado de imprimir el segundo volumen (L, I, 396, nota), en febrero de 1781 estaba listo el tercero $(L, I, 396)$ y ambos se publicaron conjuntamente el 1 de marzo de ese año (M, 322).

Los lectores tenían ante sí otros dos notables cuartos, de seiscientas cincuenta páginas cada uno con 1350 y 1316 notas a pie de página respectivamen$t^{33}$, que contenían la segunda parte de la «memorable revolución» que contempló la caída del Imperio en Occidente y «el sometimiento de Roma al poder del conquistador godo». Cada uno de ellos incluía además un espléndido y detallado mapa (de la parte occidental del imperio el segundo y de la oriental el tercero) preparado por Thomas Kitchin, «hydrographer to his Majesty». La narración del segundo volumen se articulaba en diez capítulos (XVII-XXVI) que trataban los acontecimientos del reinado de Constantino y sus sucesores hasta las guerras góticas del siglo IV, mientras que la del tercero lo hacía en doce (XXVII-XXXVIII) que llevaban el relato hasta la caída de Roma y la formación de los reinos germanos durante los siglos V y VI. La grandiosa exposición de esa «imponente revolución» culminaba, a modo de reflexión final sobre la era que moría, con unas inspiradas «Observaciones generales sobre la caída del Imperio Romano en Occidente».

La recepción de esta segunda parte de su Historia fue mucho menos polémica que la primera, pues el «celo protestante es bastante más indiferente al carácter y controversias [de la historia eclesiástica] de los siglos cuarto y quinto» (M, 322), pero la reacción del público fue también menos calurosa. Las ventas ciertamente alcanzaron los niveles del primer volumen, pero apenas hubo reacciones significativas durante los meses siguientes a su publicación (cf. L, I, 396, nota). Gibbon sospechaba que ello se debía a que ya la obra no era una novedad en sentido estricto para los lectores, y que éstos podrían estar difiriendo la lectura hasta encontrar un momento más tranquilo, como el que propiciaba el retiro veraniego al campo (L, I, 397). En cualquier caso, eso no pareció afectar ni a la vanidad ni a la estima del historiador.

${ }^{32}$ En la única carta conservada en la que habla de $D F(L, I, 365)$, con fecha de 31 de mayo de 1779 , dice: «mucho está ya hecho, pero aún queda bastante por hacer; estoy satisfecho con mi diligencia, pero no puedo perder una semana, ni casi un día».

${ }^{33}$ Vol. II: [X] + 640 + [ii]; vol. III: [x] + 640 + [ii]. 
Fuera de Inglaterra la fama de Gibbon seguía extendiéndose, pues a la traducción francesa siguieron los primeros volúmenes de una italiana ${ }^{34}$ y otra alema$\mathrm{na}^{35}$ (M, 322, 338-339).

La tirada de ambos volúmenes se agotó en pocos meses y antes de que finalizara el año se volvieron a reimprimir. La demanda exigió una segunda edición, en 1787, y hasta una tercera, en 1789. Desde el punto de vista textual apenas hay variantes significativas entre ellas. La única realmente digna de nota la justifica el propio Gibbon en sus Memorias (M, 324) y afecta a un pasaje de las «Observaciones generales...» al final del tercer volumen (pág. 636). Al parecer el rey francés Luis XVI protestó por una supuesta alusión que allí se hacía a su monarquía, por lo que Gibbon lo modificó ligeramente en la segunda y tercera ediciones.

\subsubsection{Decline and Fall IV-VI}

Con la entrega del tercer volumen Gibbon sintió que ya había cumplido con el primero de los compromisos adquiridos con su público y se permitió un descanso en su obra (M, 325-326). Pero después de casi doce meses de «libertad», en que se dedicó — según dice- a la lectura de los clásicos griegos, volvió con gran ánimo e intensidad a DF. «Algo de fama, algo de beneficio, y la garantía de entretenimiento diario fue lo que me impulsó a perseverar», le confía a su madrastra (L, II, 21). Meditó cuidadosamente el plan de trabajo, fijó unos plazos y retomó de nuevo su labor.

Algo más de un año de diligente empeño le bastó a Gibbon para redactar el manuscrito de su cuarto volumen, a pesar de la dificultad de la materia tratada («... un invierno laborioso lo dediqué a los Códigos [legales], las Pandectas y sus intérpretes modernos...» [M, 326]). Cuando se instaló en Lausanne en mayo de 1783 lo llevaba con él. Sería esa la ciudad escogida por el historiador como retiro ideal para terminar la composición de DF: «el país, las gentes, las costumbres, el idioma, congeniaban con mis gustos» (M, 327). Años atrás, durante su viaje de juventud al continente, la ciudad lo había cautivado, y ahora volvía para instalarse permanentemente ${ }^{36}$.

El cambio de domicilio interrumpió más de lo esperado el trabajo de Gibbon en DF. Sus libros tardaron meses en llegar a la ciudad y el historiador consintió no sin

${ }^{34}$ Istoria della decadenza e rovina dell' Imperio Romano, tradotta dell' inglese di Edoardo Gibbon. Pisa, 1779-1786, 9 vols. in-8‥ Gibbon la tenía completa en su biblioteca (KEYNES, G., op. cit., pág. 134). Decía preferir esta traducción italiana a la francesa antes citada (M, 339, n. 63).

${ }^{35}$ Geschichte des Verfalls und Untergangs des Römischen Reichs. Aus dem Englisches übersetzt von F. A. W. Wenck [vol. I], K. G. Schreiter [vols. 2-8], C. W. Rienberg [vols. 9-13]. Leipzig, 1779-1790. in8․ Gibbon hubiera querido poder leer alemán para apreciarla personalmente, pues le habían hablado muy bien de ella (M, 339, n. 63). La fama de esta traducción descansa principalmente en el buen trabajo de Wenck, muy superior al de los otros traductores.

${ }^{36}$ No es menos cierto, sin embargo, que con el traslado también esperaba disminuir considerablemente los gastos que suponía vivir en una ciudad como Londres, particularmente notables para un hombre de su posición (LOW, D. M., op. cit., pp. 299-301). 
agrado en cumplir con liberalidad con la sociedad de Lausanne (M, 331). Pasó un año hasta que volvió a su obra, aunque a partir de ahora ya no la dejaría hasta acabarla por completo. En una larga carta a Lady Sheffield (L, II, 119-120), esposa de su más apreciado amigo, fechada el 22 de octubre de 1784, le manifiesta su firme intención de permanecer en su retiro y terminar allí $D F$ en un plazo de tres o cuatro años, para luego regresar a Inglaterra y supervisar las pruebas de imprenta de «dos o tres volúmenes en cuarto». Y así fue exactamente.

«Seducido por la facilidad de [su] pluma» y tomada la decisión de aligerar la narración de los acontecimientos ${ }^{37}$, progresó rápidamente en la redacción de los volúmenes quinto y sexto. En la primavera de 1786 estaba ya seguro de acabar el manuscrito el verano siguiente (L, II, 143), en enero de 1787 redobla la intensidad del trabajo (L, II, 151-152) y, por fin, «llegó el día, o mejor la noche, del 27 de junio de 1787, entre las once y las doce, en que escribí las últimas líneas de la última página en el cenador de mi jardín» (M, 333). Habían pasado veintitrés años desde aquella temprana inspiración en el Capitolio y quince desde que comenzara la redacción del primer volumen.

Pero aún faltaba el trabajo de impresión y no había tiempo que perder. Su fama y su seguridad económica dependían de ello. Envió su propio manuscrito autógrafo (y no copias intermedias de amanuenses profesionales, como era la práctica habitual ${ }^{38}$ ) a Thomas Cadell $(\mathrm{M}, 334)$, ordenó sus asuntos en Lausanne y partió para Inglaterra el 29 de julio (L, II, 156). El 7 de agosto estaba ya en Londres (L, II, 157) y el 15 comenzaba la composición tipográfica y la impresión de los tres volúmenes. Los meses siguientes los pasó corrigiendo pruebas de imprenta y revisando su original a la luz de la nueva bibliografía a la que ahora, en Londres, tenía acceso (M, 336). El ritmo de las prensas fue relativamente lento en sus comienzos (la impresión del volumen cuarto costó tres meses), pero William Strahan dio instrucciones para acelerar el proceso y el trabajo de imprenta concluyó en abril de 1788 (M, 337). Cadell y Gibbon acordaron retrasar ligeramente la fecha de la publicación para hacerla coincidir con el cumpleaños de éste último, de tal manera que el 8 de mayo se pusieron a la venta los volúmenes cuarto, quinto y sexto de DF (M, 337).

La nueva y última entrega de $D F$ debió parecer imponente al público: tres "cuartos» que sumaban un total de 2037 páginas ${ }^{39}$ y 3451 notas $(1139+1135+$ 1177). La idea de «digerir» un texto de esa extensión quizás amilanó a alguno de sus viejos lectores, pero lo cierto es que Gibbon afirma que la venta fue «rápida y fácil» y que la obra fue «ampliamente leída y diversamente juzgada» (M, 337). El volumen cuarto, articulado en 6 capítulos (XXXIX-XLIV), contenía el segundo período de la Decadencia y Caída de Roma, que comenzaba con el reinado de Justiniano y se extendía al «mundo bárbaro», las «revoluciones de Persia» y la historia eclesiástica a partir del siglo V. En los dos siguientes se desarrollaba el

${ }^{37} \mathrm{DF}, \mathrm{V}$, cap. XLVIII, «Plan of the fifth and sixth volumes».

${ }^{38}$ Cf. RICO, F., op. cit., pp. 99-110.

${ }^{39}$ Vol. IV: [ii] + viii + [viii] + 620; vol. V: [iv] + 684; vol. VI: [xii] + 646 + [liii] 


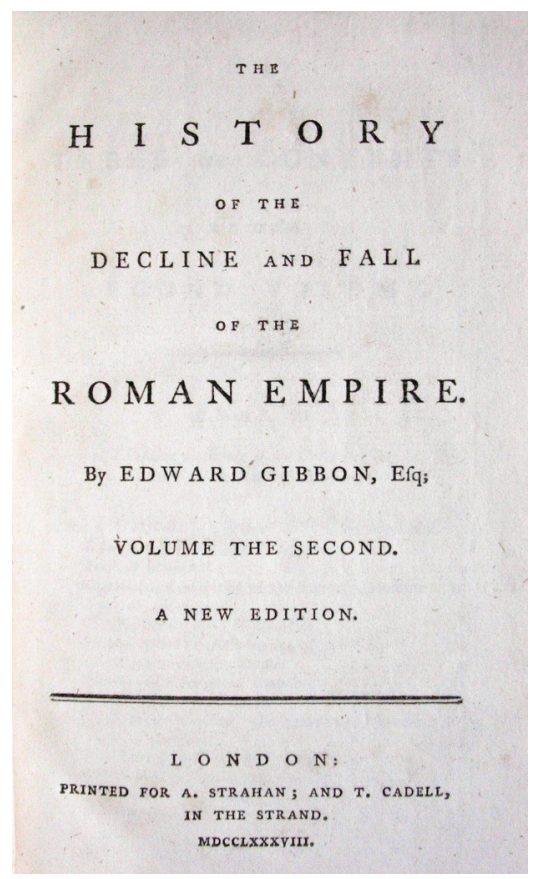

Fig. 6: Página de portada del segundo volumen de la segunda edición en 'octavo' de DF (1788).

último y más largo periodo, que abarcaba desde el renacimiento carolingio hasta la toma de Constantinopla por los turcos. La narración del volumen quinto se organizaba en 10 capítulos (XLVIII-LVII) y a través de ella se seguían las vicisitudes de la historia bizantina, el ascenso del reino franco, las conquistas africanas y asiáticas de los árabes y la formación de las naciones eslavas. El sexto volumen, estructurado en 14 capítulos (LVIII-LXXI), se abría con la historia de las cruzadas, a la que seguían el relato de la decadencia del Imperio Oriental, las guerras de conquista de los mongoles y el asedio y asalto final de Constantinopla; se cerraba con una melancólica semblanza de Roma entre los siglos XII y $\mathrm{XV}$.

La publicación fue, en general, bien acogida y al parecer la conclusión de DF causó una honda impresión a los lectores. Hubo, sin embargo, no pocas voces que acusaron al historiador de irreverente en materia religiosa e indecente en el tratamiento de ciertos personajes. Gibbon nunca comprendió las razones que movieron a esos «rígidos censores de la moral» a acusarlo de indecente, pues se había expresado - se defiende (M, 337, nota 60) — con la misma libertad en los tres primeros volúmenes y no había recibido ningún reproche. Por lo que se ve, Gibbon no reparó en que esta vez sus «enemigos» disponían de un eficacísimo instrumento para detectar las «pruebas» de su anticlericalismo o su «ligereza moral». El sexto volumen contenía un detalladísimo índice general que permitía localizar 
más fácilmente que nunca las opiniones del autor sobre los más diversos temas y personajes. Una decisión editorial —la incorporación de un índice final- estaba influyendo decisivamente en la recepción de la obra.

\subsubsection{Decline and Fall en 'octavo'}

La popularidad de $D F$ se extendió considerablemente por la inteligente decisión de Thomas Cadell de imprimir una edición en octavo. Los publicación de los tres primeros volúmenes en cuarto había hecho de Gibbon un autor famoso, y la casa editorial supuso que una edición en un formato menor y más barata se vendería bien entre lectores con una posición económica menos desahogada que la de los compradores de la edición en cuarto (cf. M, 337).

En mayo de 1783 se publicaron seis volúmenes en octavo conteniendo el texto de los tres primeros volúmenes en cuarto. La intuición de Cadell fue acertada y la demanda fue tal que la tirada estaba casi agotada en enero de 1787 (L, II, 150). Una segunda edición salió a la venta a comienzos de 1788 (Figura 6), poco antes de la publicación de los tres últimos volúmenes en cuarto de la obra. En 1790 se completaba la edición en octavo con la aparición de otros seis volúmenes. Esta vez su recepción fue tan entusiasta entre los nuevos lectores que en menos de un año hubo de publicarse una segunda edición, en el mercado en 1791.

El nuevo formato de $D F$, si bien no tan distinguido como el cuarto original (al menos según los criterios de la época), presentaba un aspecto bastante digno y cuidado y desde luego permitía una lectura sensiblemente más cómoda. Impreso también con un tipo Caslon, «double pica» para el cuerpo principal del texto y «great primer» para las notas, con espacio interlineal relativamente amplio y anchos márgenes, este «octavo» se leería sin duda con agrado.

La impresión de ambas ediciones se preparó tomando como texto base el de la quinta edición en cuarto del volumen I (1782 $)$ y el de la primera de los volúmenes II-VI (1781 y 1788 respectivamente). Desde el punto de vista textual contienen, sin embargo, revisiones tanto de carácter tipográfico (a cargo del corrector de imprenta de la casa editorial) como de contenido (a cargo naturalmente de Gibbon ${ }^{40}$ ), de tal manera que presentan diferencias con respecto a los originales en cuarto y también entre sí. Esta constatación implica que la segunda edición en octavo refleja el último estadio de un largo proceso de revisiones y correcciones y que Gibbon dio por definitiva. Se trata, por tanto, de una edición con un singular valor textual.

${ }^{40}$ Aunque en la «Advertencia a la primera edición en octavo» Gibbon parece sugerir que no introdujo alteraciones al texto, he comprobado que se han matizado o precisado un cierto número de pasajes. 


\subsubsection{Decline and Fall abreviado}

En 1789, sólo un año después de la publicación de la última entrega de DF, el impresor londinense George Kearsley puso a la venta una edición abreviada en dos volúmenes en octavo de la Historia de Gibbon ${ }^{41}$. El texto aparece muy resumido, habiéndose suprimido capítulos enteros (entre ellos todos los concernientes al Cristianismo) y desechado la totalidad de las notas. Parece tratarse de una «edición pirata» preparada sin la autorización de los titulares de los derechos de la obra y desde luego sin el visto bueno de Gibbon. Esa debió ser la razón que impulsó a Strahan y Cadell a publicar el mismo texto al año siguiente, pero ahora naturalmente bajo su firma y con una breve nota de justificación ${ }^{42}$.

\subsubsection{Epílogo}

El acuerdo que firmaron el verano de 1775 Edward Gibbon, de una parte, y Thomas Cadell y William Strahan, de la otra, devino en una de las «más honorables» empresas editoriales del siglo XVIII. A Gibbon le procuró no sólo fama universal sino la tranquilidad económica que siempre deseó (L, II, 152). Ningún autor había sido tan bien pagado por su trabajo intelectual como él, que recibió de sus editores la enorme suma de 9.000 libras por los seis volúmenes de $D F^{43}$. Tampoco ningún autor había sido tan rentable para Cadell y Strahan como él. Según mis estimaciones, se vendieron al menos 17.500 ejemplares en cuarto, que suponen otras tantas guineas. A ello hay que sumar los beneficios de las dos ediciones en octavo de 12 volúmenes cada una, con una tirada total de no menos 24000 ejemplares. Decline and Fall fue, sin duda alguna, el mayor éxito editorial del mercado inglés del último tercio del siglo XVIII.

\subsection{Decline and Fall desde la muerte de Gibbon (1794)}

\subsubsection{La edición de Henry Milman}

En 1804 expiraron los derechos editoriales que la firma Cadell conservaba sobre DF, lo que propició la aparición en el mercado de un cierto número de reimpresiones en octavo de la obra. Se trata de ediciones muy poco cuidadas desde el punto de vista textual, que se suceden durante las dos primeras décadas del siglo XIX. La que publicó William Allason junto con otros veinticuatro editores en Londres en 1816 se reimprimió no menos de siete veces entre esa fecha y 1823.

${ }^{41}$ Gibbon's History of the Decline and Fall of the Roman Empire in Six Volumes, Quarto, Abridged in Two Volumes, Octavo. London, 1789. I ([xii] + 570); II ([xii] + 562).

${ }_{42} \mathrm{Mr}$. Gibbon"s History of the Decline and Fall of the Roman Empire, Abridged in two Volumes. London, 1790 .

${ }^{43}$ KALLENDORF, C., «patronage, modern», en SUAREZ, M. F. y WOUDHUYSEN, H. R. (eds.), op. cit., II, pp. 1009-1010. 


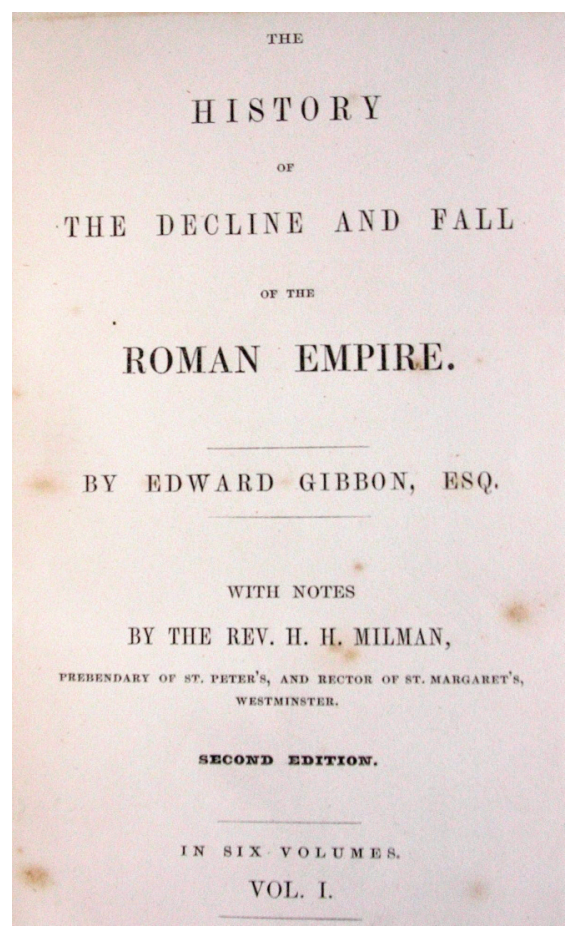

Fig. 7: Página de portada del primer volumen de la segunda edición de H. Milman de DF (1846).

Dejando de lado estas versiones de escaso valor, Decline and Fall se ha difundido y leído desde la muerte del historiador a través de tres ediciones inglesas principales.

La más antigua fue fruto del acuerdo alcanzado entre la prestigiosa casa editorial londinense John Murray ${ }^{44}$ y el reverendo Henry Hart Milman (1791-1868). Por esas fechas Milman era un sacerdote con cierto prestigio en el seno de la Iglesia de Inglaterra, poseía una excelente educación clásica (adquirida en Eton y Oxford) y estaba trabajando en la historia del Cristianismo ${ }^{45}$. Debieron parecer buenas referencias para asumir una nueva edición de DF. Como quiera que fuese, entre 1838 y 1839 se publicaron doce volúmenes en octavo con la Historia de Gibbon, refundidos en seis en una versión revisada por el propio Milman en $1846^{46}$ (Figura

${ }^{44}$ SHILLINGSBURG, P. L. y SUAREZ, M. F., «Murray family», en SUAREZ, M. F. y WOUDHUYSEN, H. R. (eds.), op. cit., II, pp. 951-952.

45 [Editorial], «Milman, Henry Hart», Encyclopædia Britannica, 18, 1911 11, pág. 476.

46 The History of the Decline and Fall of the Roman Empire. By Edward Gibbon, Esq. With Notes [+ 14 Maps] by the Rev. H. H. Milman. Second Edition. In Six Volumes. London, John Murray, 1846. in-8. I (xlii + 600); II (xii + 559); III (xv + 543); IV (xv + 524); V (xv + 506); VI (xv + 498 [+ 16 pp. list of books]). Mis citas son conformes a esta edición. 
7). Durante cincuenta años fue la edición de referencia para los lectores de lengua inglesa y su texto se reimprimió incontables veces a lo largo ese tiempo ${ }^{47}$.

Se trata de una edición en que se aprecia un notable cuidado y una preocupación por fijar un texto más autorizado que los que por entonces circulaban en el mercado editorial. Es difícil determinar qué texto base siguió para cada uno de los volúmenes, pues en ningún momento lo especifica Milman, pero constato la corrección de un cierto número de erratas presentes aún en las ediciones en cuarto y octavo publicadas en vida de Gibbon.

Pero esta nueva edición de $D F$ no había sido ideada sólo para suplir las deficiencias de las anteriores. El reverendo Milman tenía ciertamente en gran estima a Gibbon y creía sinceramente que una obra histórica tan grandiosa merecía ser leída en una buena edición. Ahora bien, también pensaba que las muchas virtudes de Gibbon como historiador no deberían hacer pasar por alto lo que juzgaba imprecisiones, errores de interpretación, defectos o incluso mala fe en las opiniones, singularmente en lo que se refería a su tratamiento del Cristianismo. Y de esta manera Milman se sentía legitimado para presentar a sus lectores una edición diseñada en particular para «corregir», mediante las oportunas notas aclaratorias, la «desafortunada y equivocada» exposición del Cristianismo y, en general, para «actualizar» los detalles de la narración con las aportaciones más recientes de la historiografía. Su única intención con este proceder, sigue explicándose en el Prefacio, es simplemente establecer la «verdad». Milman no se conformó, sin embargo, con incorporar al texto de $D F$ sus propias anotaciones críticas, también añadió las que había publicado François Guizot (1787-1874) ${ }^{48}$, «distinguido historiador» y «sincero cristiano», en la segunda edición (1828) de su traducción francesa $^{49}$.

El celo de Milman en materia religiosa se tradujo en un corpus de notas que en los capítulos XV y XVI duplica y hasta triplica en densidad al del propio Gibbon, en el que llega a apelar al deber moral de los lectores, como buenos cristianos, de condenar sin paliativos el último de tales capítulos en su totalidad, «impropio de un filósofo y un hombre de humanidad» (vol. I, pág. 527, nota) ${ }^{50}$. La mano del reverendo se deja sentir igualmente en el índice final, al que incorpora hasta una entrada con el lema «errores detectados en DF» (vol. VI, pp. 456-458). No menos significativo del espíritu que preside esta edición son las cubiertas originales de

${ }^{47}$ La más popular de ellas fue la que editó William Smith para Murray en 8 volúmenes, con notas adicionales del propio Smith. La primera edición se publicó en 1854-1855. También circuló con éxito una edición abreviada del mismo editor que se publicó con el título de The Student" s Gibbon y apareció en el mercado en 1856.

${ }^{48}$ REEVE, H. y SHOTWELL, J. T., «Guizot, François Pierre Guillaume», Encyclopædia Britannica, 12, $1910^{11}$, pp. 705-709.

${ }^{49}$ Histoire de la décadence et de la chute de l' Empire romain, traduite de l' anglais d" Édouard Gibbon. Paris, 1828,13 vols., in- $8^{\circ}$.

50 Circulaba ya por entonces una curiosa versión expurgada de $D F$, con omisión de «todos los pasajes de tendencia irreligiosa o inmoral»: BOWDLER, T. (ed.), Gibbon" s History of the Decline and Fall of the Roman Empire: for the use of families and young persons [5 vols.]. Reprinted from the original text, with the careful omission of all passages of an irreligious or inmoral tendency. London, 1826. 


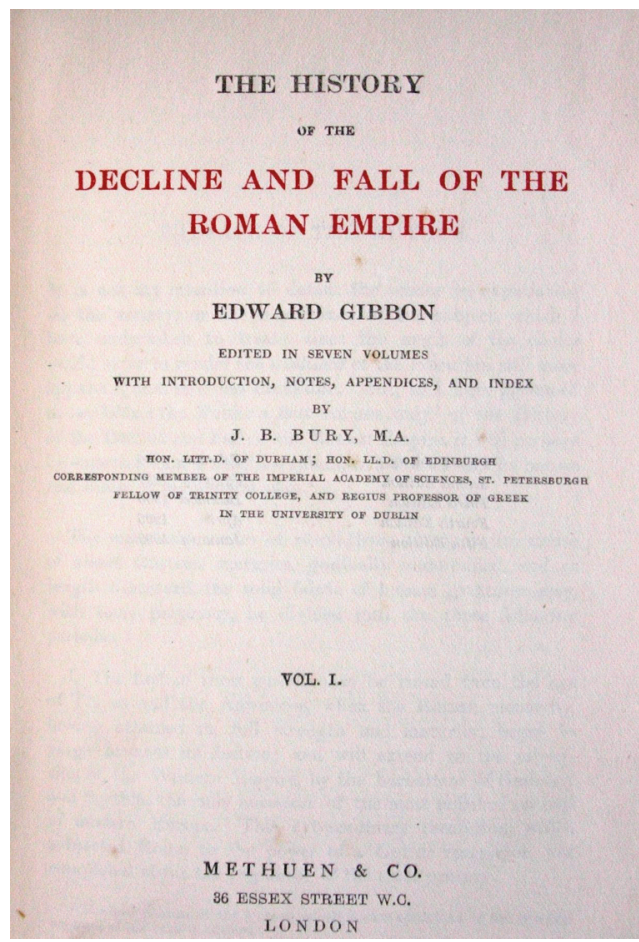

Fig. 8: Página de portada del primer volumen de la primera edición de J. Bury de DF (1896).

1846. Tanto la delantera como la trasera llevan impreso el legendario labarum, estandarte con la cruz que supuestamente portaba el ejército de Constantino (cf. DF, II, cap. XX).

Durante toda la larguísima era Victoriana el texto de DF se leyó con las notas severas y reprobatorias de Milman y Guizot, lo que sin duda comprometió la reputación del viejo historiador. Gibbon, que tan brillantemente había defendido su honorabilidad contra los «rígidos censores de la moral», no habría nunca imaginado peor suerte para la difusión de su obra.

\subsubsection{La edición de John Bury}

La fortuna de Gibbon cambió de signo con el comienzo del siglo XX, cuando una nueva edición desplazó del mercado editorial la de Milman. Con motivo del centenario de su muerte (1894) la firma Methuen \& Co. ${ }^{51}$, establecida en Londres

${ }^{51}$ LONGWORTH, K., «Methuen \& Co.», en SUAREZ, M. F. y WOUDHUYSEN, H. R. (eds.), op. cit., II, pág. 929. 
en 1889, encargó a John Bagnell Bury (1861-1927), Regius Professor de griego de la Universidad de Dublín e historiador del Imperio Romano Tardío52, una nueva edición de DF. La obra se imprimió en siete volúmenes en «octavo menor» y salió a la venta entre los años 1896 y $1900^{53}$ (Figura 8). Ningún otro «regalo de cumpleaños» habría hecho más feliz a Gibbon.

El profesor Bury preparó, como filólogo con oficio, una edición de acuerdo con los más exigentes principios de la crítica textual de su época que incorporaba, y aquí se muestra como historiador experimentado, el nuevo conocimiento histórico acumulado en un siglo de investigaciones. Las imputaciones de orden moral o religioso como las de Milman naturalmente no tenían cabida en una edición académica como esta, y quedaban expresamente excluidas como «meras impertinencias» (vol. I, pág. xli).

Para establecer el texto, Bury cotejó las ediciones originales en «cuarto» (cf. vol. I, pp. xxxii-xxxiv; vol. IV, pág 529), pero he podido determinar que utilizó finalmente la quinta edición (1782) del volumen I, la tercera (1789) de los volúmenes IIIII y la primera (1788) de los volúmenes IV-VI. La distribución de los capítulos en volúmenes no se corresponde, sin embargo, con los originales; tampoco la numeración de las notas coincide con las de aquellos, pues las de Bury se intercalan con las de Gibbon (aunque se distinguen naturalmente unas de otras).

El texto se presenta cuidadosamente revisado y corregido en no pocas instancias, con cierta licencia a la hora de fijar la puntuación y modernizar las grafías de unas pocas palabras (cf. vol. I, pp. xlii-xliii). Se acompaña (vol. I, pp. xxxiv-xxxviii) de anotaciones autógrafas —inéditas hasta ese momento- del propio Gibbon a un ejemplar suyo de $D F$, conservado en manos privadas y mostrado en 1895 en el British Museum con ocasión del centenario del autor ${ }^{54}$.

Como historiador, el profesor Bury anotó profusamente el texto de DF con observaciones, correcciones y bibliografía y añadió apéndices a seis de los volúmenes con noticias de las autoridades empleadas por Gibbon y eruditas notas complementarias sobre las más diversas cuestiones históricas tratadas en la obra. Culminó su monumental tarea añadiendo las correspondencias pertinentes entre las ediciones de las fuentes utilizadas por Gibbon y las más modernas establecidas a partir del siglo XIX, así como diez mapas y planos históricos. Dos detalladísimos índices finales a cargo de su propia esposa completan la edición; el primero (que integra y desarrolla el original; cf. 3.2.4) atañe al texto y las notas, el segundo a los apéndices.

Todas estas aportaciones y materiales suplementarios promovieron y enriquecieron singularmente la lectura de DF como obra de historia y prolongaron su

52 BAYNES, N. H., A Bibliography of the Works of J. B. Bury. Cambridge, 1929.

53 The History of the Decline and Fall of the Roman Empire by Edward Gibbon. Edited in seven volumes with introduction, notes, appendices, and index by J. B. Bury, M. A. London, Methuen \& Co. in- $8^{\circ}$. I (1896, Ixviii + 464 pp.); II (1896, xiv + 570 pp.); III (1897, xiii + 508); IV (1897, xiii + 546); V (1898, xv + 543); VI (1898, xV + 560); VII (1900, xii + 508).

${ }^{54}$ KEYNES, G., op. cit., pág. 134. 
autoridad. El espléndido trabajo editorial del profesor Bury fue reconocido de inmediato y su edición se convirtió en el texto de referencia para tres generaciones de lectores.

\subsubsection{La edición de David Womersley}

Una vez más otro aniversario cambiaría de nuevo la fortuna de Edward Gibbon. Con ocasión de su bicentenario, la editorial londinense Penguin Press ${ }^{55}$ encomendó a David Womersley, Thomas Warton Professor de Literatura Inglesa de la Universidad de Oxford, la preparación de una nueva edición de DF. Se publicó en tres volúmenes en «octavo menor» en $1994^{56}$, justamente cuando se cumplían los doscientos años de la muerte del autor.

La vocación expresamente declarada de la edición es la de presentar $D F$ tal como lo conocieron sus primeros lectores, en un texto «no modernizado». El profesor Womersley afronta su tarea editorial considerando a Decline and Fall como un «clásico», cuya importancia como tal para los lectores modernos es «hasta cierto punto independiente de la precisión de sus referencias o la autoridad actual de sus juicios» (vol. I, pág. cviii). En consecuencia propone una edición que quiere ser lo más fiel posible al espíritu del original, con todas sus peculiaridades e inconsistencias.

Siguiendo estos principios editoriales rectores, Womersley reimprimió los textos de los originales en cuarto (índice final incluido) corrigiéndolos escrupulosamente a la luz de la colación de todas las variantes de cada edición. Su texto base para el volumen I es el de la quinta edición de 1782, en su estado a; para el resto (II-VI) sigue las primeras ediciones de cada uno de ellos (1781 y 1788 respectivamente). Todas las desviaciones de las ediciones seguidas se señalan oportunamente en apéndices. Incorpora, también en apéndice (vol. I), una interesante selección de las variantes más importantes y sustanciales del volumen I publicadas entre 1776 y 1789 . Por lo demás, el editor respeta estrictamente la puntuación, acentuación y grafías originales. Es de notar, todavía en cuanto a cuestiones de orden textual, que imprime igualmente (vol. III, apéndice 2) las notas manuscritas marginales de dos ediciones de DF del propio Gibbon que se conservan en la British Library ${ }^{57}$. En atención a la «fidelidad al original», ninguna anotación editorial acompaña al texto de Gibbon.

La edición se completa con una generosa y lúcida introducción al autor y su obra, bien contextualizada en las corrientes intelectuales de la época (vol. I), con el

${ }^{55}$ HARE, S., «Penguin Books / Classics», en SUAREZ, M. F. y WOUDHUYSEN, H. R. (eds.), op. cit., II, pág 1014.

56 Edward Gibbon. The History of the Decline and Fall of the Roman Empire. Edited by David Womersley. London, Allan Lane The Penguin Press. 1994. I (cxiii + 1114); II (v + 1009); III (v + 1353).

${ }^{57}$ Que no se corresponden con las que recoge Bury, de lo que se deduce que existen al menos tres ediciones distintas de DF con anotaciones marginales del propio Gibbon. 
texto de la segunda edición de $A$ Vindication... (cf. 3.2.2) y con un utilísimo «Índice Bibliográfico» de los autores y obras citados por Gibbon (vol. III).

Si la edición de Bury apela a la apreciación de $D F$ como «clásico» de la historiografía, ésta de Womersley propone una lectura de la obra como «clásico» de la literatura europea.

\section{LAS TRADUCCIONES ESPAÑOLAS DE DECLINE AND FALL}

\subsection{La traducción de José Mor de Fuentes}

Decline and Fall no ha tenido mucha fortuna en los países de lengua española. La únia traducción castellana íntegra sigue siendo la que preparara José Mor de Fuentes con el título de Historia de la decadencia y ruina del Imperio Romano y publicara en Barcelona Antonio Bergnes en ocho volúmenes en "octavo menor» entre 1842 y 1847.

Mor de Fuentes (1762-1848) era un hombre de letras formado en la universidad de Zaragoza y la academia militar de Barcelona, con buenas aptitudes para los idiomas y con ciertas aspiraciones literarias. La traducción fue el sostén económico principal de los últimos años de su vida, instalado en Barcelona y con encargos regulares de la imprenta de Antonio Bergnes, ilustrado editor catalán $n^{58}$. A esos años corresponde la traducción de $D F$, que según declara en el «Prólogo» funda en la edición inglesa de Milman (la primera de 1838) y presenta con las notas originales -al final de cada capítulo- de Gibbon, Guizot y del propio reverendo inglés.

El mérito principal de Mor de Fuentes es el de haber tratado de acercar a los lectores españoles la obra del historiador inglés, que como ya se ha visto se podía leer desde hacía tiempo en francés, alemán e italiano. Pero si lo que se juzga es la calidad de su traducción, como corresponde en este caso, habrá que cuestionar seriamente el valor de su trabajo. Desde un punto de vista general, el principal problema es el de la escasa fidelidad a la letra y espíritu del texto inglés, hasta el punto de que es realmente difícil creer que se está leyendo a Gibbon. Mor de Fuentes adapta la prosa del historiador a su propio estilo (con tendencia al uso de expresiones grandilocuentes y acumulación de superlativos y formas adjetivales de su propio cuño, entre otras particularidades) forzándola hasta desnaturalizarla por completo. El texto de DF sufre adicionalmente toda suerte de alteraciones en manos de Mor y apenas se reconoce en su traducción el estilo característico del autor inglés o la línea discursiva de su narración histórica. La «versión» castellana

58 Sobre Mor de Fuentes y los ambientes intelectuales y editoriales en los que trabajó se verá FRANCÍ VENTOSA, C., «Reflexiones en torno a la traducción de la Historia de la decadencia y ruina del Imperio Romano por José Mor de Fuentes», publicado en versión electrónica en www.saltana.org /1/tsr/51.html. 
de Mor de Fuentes, en suma, se aleja tanto del original que pretende reflejar que perjudica severamente su fama y reputación.

No tengo noticias de la existencia de ninguna reimpresión de la traducción de Mor hasta que la casa Turner volvió a sacarla al mercado en una edición facsímil, también en ocho volúmenes, en el año 1984. Si así fuera, ello hablaría subsidiariamente de la escasísima y puntual difusión que DF tuvo en España hasta tiempos bien recientes. La tirada original de la imprenta Bergnes, seguramente no más de 1500 ejemplares, tendría una vida necesariamente muy limitada, de tal manera que me parece poco probable que circulara ya en la segunda mitad del siglo XIX.

En el año 2006 la misma editorial Turner puso a la venta, ahora en cuatro volúmenes, lo que se presenta confusamente tanto como una «edición revisada y actualizada» del texto de Mor de Fuentes como una «reelaboración del texto, cotejado con el original inglés» (sic.). Lo que en realidad se hizo fue simplemente «remozar» la vieja traducción de Mor modificando aquí y allá (de forma aparentemente arbitraria) algunos giros o expresiones del traductor por otros que se debieron suponer más modernos o acordes con nuestros tiempos. El resultado de esta desafortunada «operación quirúrgica» fue la creación de una suerte de texto híbrido que no responde ya a las exigencias mínimas de rigor de una traducción de una obra clásica.

\subsection{La traducción de José Sánchez de León Menduiña}

En el mes de abril de este año 2012 la editorial Atalanta publicó el primer volumen (de los dos anunciados) de una traducción de DF a cargo de José Sánchez de León Menduiña. Se trata de un volumen en octavo que contiene los 36 primeros capítulos del texto de Gibbon e incluye un «Prólogo del traductor» a la vida y obra del historiador.

Sobre el traductor no he podido recabar dato alguno, pero por el resultado de su labor se deduce una escasa familiaridad con los principios básicos de la edición y traducción literarias e igualmente con el autor y el periodo histórico de su obra. Lo primero es bien evidente por la ligereza e insuficiencia con que se afronta la traducción del texto y lo segundo particularmente por la obsoleta e impropia presentación de Gibbon y su Historia.

El traductor establece su texto base sin conocimiento alguno de la tradición textual de $D F$ ni de la edición de referencia actual de David Womersley (cf. pág. $\mathrm{XCVI}$ ). En estas condiciones dice regirse por la reimpresión de la edición de Bury que publicó la Biblioteca Everyman en los años 1993-1994. Afirma no estar de acuerdo, sin embargo, con el criterio de la edición Everyman en cuanto a presentar «las cuantiosas notas a pie de página» y que «[ha] preferido desecharlas y colocar únicamente las decisivas para entender y aclarar el texto principal, así como las que han supuesto modificaciones de errores cometidos por el propio Gibbon y las debidas a descubrimientos posteriores [sic!]» (pág. CV). 
Si la posición de partida del traductor ante su texto es ya de por sí suficiente prueba de los límites de su competencia, no lo es menos el resultado de su trabajo. Las deficiencias comienzan ya en el propio título (Decadencia y caída del Imperio Romano, en lugar de Historia de la decadencia...) y afectan a la organización de los parágrafos (subdivisiones de los capítulos), las notas y la traducción propiamente dicha. Ni en el índice ni en el cuerpo del texto se respetan los parágrafos tal como los estableció originalmente Gibbon, de tal manera que se omiten muchos, se altera la denominación de otros o bien se agrupan varios de ellos. En cuanto a las notas, se ha desechado casi la totalidad de las 7835 originales, que suponen entre un tercio y un cuarto del texto de DF. Sánchez de León no parecer ser consciente de la importancia del aparato erudito para una obra de historia, y particularmente para la de Gibbon. Pero el despropósito no acaba ahí, pues no hay criterios que justifiquen las pocas notas que permanecen, así como tampoco la presencia de alguna sin autoría reconocida (pp. 21,23$)$ u otras que se remontan a la primera edición Everyman de 1910 (por ejemplo, pp. 41, 45, 59, 69 [con bibliografía de la primera mitad del siglo XIX]). Con respecto a la traducción, he podido comprobar su escasa o nula fidelidad al texto inglés en un buen número de pasajes, expresiones y palabras concretas.

La pobre formación histórica de Sánchez de León y su poco conocimiento del estado actual de los estudios «gibbonianos» quedan en evidencia en el «Prólogo del traductor». Presenta allí una suerte de estado de la cuestión sobre el autor y su obra que en términos generales remite a ciertos ambientes intelectuales de la segunda mitad del siglo XIX y comienzos del XX, citando como actuales a historiadores de esa época - aunque guardándose siempre de indicar fechas- (como Carlyle, Harnack o Cumont: pp. XCIX-CI). No aporta, por otro lado, ni una sola referencia bibliográfica precisa de las autoridades que cita ni ofrece bibliografía especializada alguna sobre Gibbon ni $D F^{59}$.

Edward Gibbon, preocupado siempre por mantener su buen nombre como historiador y hombre de letras, era muy sensible a la calidad y los méritos de las traducciones de su Historia que aparecían en el continente. Al respecto decía que le hubiera gustado poder suprimir todas aquellas versiones imperfectas que salían al mercado, que a la par que extendían el nombre del autor perjudicaban su reputación $(\mathrm{M}, 339)$. Después de haber revisado las traducciones españolas de DF es difícil no imaginar la disconformidad con la que las habría recibido Gibbon. Definitivamente The History of the Decline and Fall of the Roman Empire no ha tenido mucha fortuna en nuestra lengua.

${ }^{59}$ Al margen de las deficientes «versiones» de Mor de Fuentes y Sánchez de León, sólo puede leerse a Gibbon en castellano en la traducción que originalmente publicara la editorial Alba (Historia de la decadencia y caída del Imperio Romano [Edición abreviada de Dero A. Saunders. Traducción de Carmen Francí Ventosa]. Barcelona, 2001) de una edición abreviada de DF a cargo de Dero A. Saunders (The Portable Gibbon: The Decline and Fall of the Roman Empire. New York, 1952). Se trata de un texto que recoge meramente una selección de capítulos, resumidos y sin ninguna de las notas de la edición inglesa, de la primera mitad del original. 
